\title{
The Effect of Aging on the Degree of Association Between the Thyroid Hormones and the Outcomes of Ischemic Stroke: A Restrospective Study
}

Yamin Lu ( $\nabla$ xyluyamin1@163.com )

Hebei General Hospital

Fang Chen

Hebei General Hospital

Feng Mo

Hebei General Hospital

Guangxia Liu

Hebei General Hospital

Zhan Hou

Hebei General Hospital

Lianchun Zhao

Hebei General Hospital

Lin Liu

Hebei General Hospital

\section{Research Article}

Keywords: Cerebrovascular Disease, Stroke, Thyroid Hormone, Aging, Prognostication, Biomarkers

Posted Date: January 26th, 2022

DOI: https://doi.org/10.21203/rs.3.rs-1204942/v1

License: (9) (i) This work is licensed under a Creative Commons Attribution 4.0 International License.

Read Full License 


\section{Abstract}

\section{Background}

Acute Ischemic Stroke is a leading cause of death worldwide. Many clinical studies have focused on the correlation between thyroid axis hormones and disease outcomes, but results remain controversial. One possible reason for the conflicting results is that the association among prognostic factors varies in different age groups. our study is focused on the effect of aging on the association and the degree of correlation between thyroid-related hormones and ischemic stroke outcomes.

\section{Methods}

The retrospective study was performed on 1025 stroke patient records. Included patients were in three age groups: Above 85 Group, $65-80$ Group, and Below 65 Group. Spearman's rank correlation was performed to evaluate the association and the degree of correlation between thyroid hormones and the NIHSS score.

\section{Results}

A total of 604 patients meeting study criteria were included in the study. Excluding reasons were previous stroke, thyroid-related diseases, cancer, chronic liver diseases, and other reasons. T3 was found to be significantly associated with NIHSS score except in the Below 65 Group. fT3 was inversely related to the NIHSS in all age groups. TSH had similar association except in the Above 80 Year Group. T4 and fT4 didn't have significant association with disease severity, except in the 65-80 Year group for fT4.

\section{Conclusions}

Aging had a significant effect on the association and the magnitude of correlation between thyroid hormones and stroke outcomes. The more delicate age-dependent grouping methods could provide more accurate and clinically meaningful insights into the prognostic values of biomarkers.

\section{Highlights}

1. Many clinical studies have focused on the correlation between thyroid axis hormones and disease outcomes, but results remain controversial.

2. A non-significant association between any two factors in the entire population might present significant results in sub-group analysis.

3. Aging had a significant effect on the relationship and the magnitude of correlation between thyroid hormones and stroke outcomes.

\section{Introduction}


Acute Cerebrovascular Disease (ACD) is a leading cause of death worldwide [1]. Acute Ischemic Stroke (AIS) is a common form of ACD, and it's associated with poor prognostic outcomes, long-term disability, and mortality. Accurate risk assessment on the severity and early prognostication can help optimize therapeutic options. It is clinically meaningful to evaluate various biomarkers for risk stratification and outcome prediction[2].

The thyroid axis hormones have been considered to be highly correlated to the severity and prognostic outcome of ischemic stroke. Thyroid-related hormones are known to play an important role in many acute conditions, including acute cardiac events, respiratory failure from pulmonary disorders, brain tumor surgery, stroke, etc [3-6]. The endocrine changes in anterior pituitary axis hormones are pathophysiologically relevant to the severity and clinical outcomes of ischemic stroke. The key thyroid hormones measured in the blood serum are thyroid-stimulating hormones (TSH), total triiodothyronine (T3), total thyroxine (T4), free T3, free T4, etc.

In a normal endocrine system, the TSH can trigger the thyroid gland to synthesize T4, which can be converted to T3 by enzyme type 1 iodothyronine-5-deiodinase [7]. The T3 was then transformed to free T3, the bioactive form of T3 into the cells. A stroke event can trigger stress response by releasing stressors that often cause neuroendocrine disturbance leading to immune disorders so that the body becomes less resistant to infections resulting in a poor prognosis [8].

Several clinical studies have focused on the correlation between thyroid axis hormones and disease outcomes, but results remain controversial. Several studies concluded that lower initial serum T3 values within the normal range were negatively correlated to the National Institute of Health Stroke Scale (NIHSS) score, as an indication of baseline severity of stroke victims [9]. Other studies revealed that worse stroke severity was often associated with higher T4 [10], lower fT3 [11], and lower fT3/fT4 ratios [12], but other analyses did not agree with these results [13][14].

One possible reason for the conflicting results is that the association among prognostic factors varies in different age groups. Li et al have reported that the T3 hormone is more clinically meaningful in the elder patients [15]. It is known that both age and NIHSS scores have a negative relationship with thyroid functions, which means that worse thyroid function is associated with older age and higher initial NIHSS score (worse severity) for stroke patients [16]. However, our study is focused on the effect of aging on the association and the degree of correlation between thyroid-related hormones and ischemic stroke outcomes.

\section{Materials And Methods}

\section{Study Design and Patient Selection}

The retrospective study was performed on records from Hebei General Hospital (Shijiazhuang, Hebei, China) between Jan 2020 to June 2021. Patients diagnosed with Acute Ischemic Stroke (AIS) within 72 hours of symptom onset were included in the study. AIS was defined as sudden onset of neurological 
deficits that are lasting greater than 24 hours and that is confirmed by CT scans. Patients included in the study had both thyroid function tests and NIHSS evaluation performed within 24 hours of hospital admission. Patients with previous stroke history were not included in this study, because previously distorted thyroid functions might complicate the accuracy of the statistical analysis. Exclusion criteria include medical conditions such as overt hypothyroidism, hyperthyroidism, currently receiving drug treatments for a medical illness affecting thyroid functions, chronic renal or liver failure, acute infectious or inflammatory diseases, cancer, hematological disease, and other malignancies. Included patients were divided into three age groups: Above 85 Group, 65-80 Group, and Below 65 Group.

\section{Clinical Variables}

The following demographic and clinical data were recorded: age, gender, risk factors such as smoking and alcohol, disease histories including hyperlipidemia, corona artery disease, diabetes mellitus, arterial fibrillation, and hypertension. Routine laboratory testing was done, and thyroid function tests examined TSH, total triiodothyronine (T3), total thyroxin (T4), free T3, and free T4 levels. Normal ranges of thyroidrelated hormones were 0.35-4.94 IU/L for TSH 0.57-1.59 $\mathrm{ng} / \mathrm{mL}$ for T3, 4.87-11.72 $\otimes / \mathrm{dL}$ for T4, 1.71-3.71 $\mathrm{pg} / \mathrm{mL}$ for free $\mathrm{T} 3$, and $0.7-1.48 \mathrm{ng} / \mathrm{dL}$ for free $\mathrm{T} 4$. Stroke neurological severity was assessed by the NIHSS score. An NIHSS score less than 8 was considered mild, a score between 8 to 14 was moderate, and a score more than 14 was assessed as severe. The NIHSS was evaluated by a neurologist upon admission.

\section{Statistical Analysis}

The IBM SPSS Statistics 23 software for Windows (SPSS Inc., Chicago, IL, USA) was used for statistical analysis. Quantitative variable data were expressed as median (interquartile range, IQR) or mean \pm standard deviation. Qualitative variables were expressed as numbers (percentages). Spearman's rank correlation was performed to evaluate the association between thyroid hormones and the NIHSS score. All testing was two-tailed, and a P-value less than 0.05 was considered to be statistically significant.

\section{Results}

The study reviewed 1025 consecutive patients admitted to the Department of Neurology within 72 hours of Acute Ischemic onset. As shown in Figure 1, only 604 patients meeting study criteria were included in the study. A total of 421 patients were excluded from the study. Exclusion reasons are: previous stroke $(n=215)$, thyroid-related diseases $(n=39)$, cancer $(n=66)$, chronic liver or liver failure $(n=15)$, inflammatory or infectious diseases $(n=42)$, data insufficiency $(n=34)$, other reasons $(n=10)$.

Fig. 1 Flow Chart Demonstrating Study Design

Baseline and demographic characteristics are summarized in Table 1. The gender ratios in each age group were not statistically different, which indicated that gender did not play a significant role in stroke onset in terms of age. Smoking and alcohol intake, as risk factors, accounted for greater percentages of stroke patients in the Below 65 group ( $50.9 \%$ and $36.1 \%$ respectively) than those in the Above 80 group 
(34.8\% and $30.3 \%$ respectively). Regarding disease history, greater percentages of AlS patients in the Below 65 group had Hyperlipidemia, Corona Artery Disease, and Diabetes Mellitus than those in the elder patient groups. However, a larger portion of stroke patients above 80 had Hypertension and Arteria Fibrillation, compared with those in younger age groups. The average thyroid-related hormone levels varied among age groups. Only T3 and fT3 levels exhibited a decreasing trend as age increased, which corresponded with results published previously [15]. 
Table 1

Basic Demographic Characteristic in Different Age Groups.

\begin{tabular}{|c|c|c|c|c|c|}
\hline & & Total & $\begin{array}{l}\text { Group A } \\
\text { (Above } \\
80 \text { ) }\end{array}$ & $\begin{array}{l}\text { Group B } \\
\text { (65-80 } \\
\text { Years) }\end{array}$ & $\begin{array}{l}\text { Group C } \\
\text { (Below } 65 \\
\text { Years) }\end{array}$ \\
\hline \multicolumn{2}{|l|}{ No. of Patients (n) } & 604 & 66 & 200 & 338 \\
\hline \multicolumn{2}{|l|}{$\begin{array}{l}\text { Age (Years),Media } \\
\text { (IQR) }\end{array}$} & $\begin{array}{l}63(54- \\
72)\end{array}$ & $\begin{array}{l}83(81- \\
86)\end{array}$ & $\begin{array}{l}71(68- \\
75)\end{array}$ & $55(49-60)$ \\
\hline \multirow[t]{2}{*}{ Sex } & Male (n, \%) & $\begin{array}{l}374 \\
(61.9 \%)\end{array}$ & $\begin{array}{l}37 \\
(56.1 \%)\end{array}$ & $\begin{array}{l}118 \\
(59.0 \%)\end{array}$ & $\begin{array}{l}219 \\
(64.8 \%)\end{array}$ \\
\hline & Female $(\mathrm{n}, \%)$ & $\begin{array}{l}230 \\
(38.1 \%)\end{array}$ & $\begin{array}{l}29 \\
(43.9 \%)\end{array}$ & $\begin{array}{l}82 \\
(41.0 \%)\end{array}$ & $\begin{array}{l}119 \\
(35.2 \%)\end{array}$ \\
\hline \multirow[t]{2}{*}{ Risk Factors } & Smoking (n, \%) & $\begin{array}{l}290 \\
(48.0 \%)\end{array}$ & $\begin{array}{l}23 \\
(34.8 \%)\end{array}$ & $\begin{array}{l}95 \\
(47.5 \%)\end{array}$ & $\begin{array}{l}172 \\
(50.9 \%)\end{array}$ \\
\hline & Alcohol (n, \%) & $\begin{array}{l}208 \\
(34.4 \%)\end{array}$ & $\begin{array}{l}20 \\
(30.3 \%)\end{array}$ & $\begin{array}{l}66 \\
(33.0 \%)\end{array}$ & $\begin{array}{l}122 \\
(36.1 \%)\end{array}$ \\
\hline \multirow[t]{5}{*}{ Disease History } & Hyperlipidemia $(\mathrm{n}, \%)$ & $\begin{array}{l}271 \\
(44.9 \%)\end{array}$ & $\begin{array}{l}18 \\
(27.3 \%)\end{array}$ & $\begin{array}{l}74 \\
(37.0 \%)\end{array}$ & $\begin{array}{l}179 \\
(52.9 \%)\end{array}$ \\
\hline & $\begin{array}{l}\text { Corona Artery Disease (n, } \\
\%)\end{array}$ & $\begin{array}{l}51 \\
(8.4 \%)\end{array}$ & $4(6.1 \%)$ & $15(7.5 \%)$ & $32(9.5 \%)$ \\
\hline & Diabetes Mellitus (n, \%) & $\begin{array}{l}162 \\
(26.8 \%)\end{array}$ & $\begin{array}{l}15 \\
(22.7 \%)\end{array}$ & $52(26 \%)$ & $95(28.1 \%)$ \\
\hline & Artria Fibrillation (n, \%) & $\begin{array}{l}39 \\
(6.5 \%)\end{array}$ & $\begin{array}{l}10 \\
(15.2 \%)\end{array}$ & $16(8.0 \%)$ & $13(3.8 \%)$ \\
\hline & Hypertension (n, \%) & $\begin{array}{l}364 \\
(60.3 \%)\end{array}$ & $\begin{array}{l}46 \\
(69.7 \%)\end{array}$ & $\begin{array}{l}132 \\
(66.0 \%)\end{array}$ & $\begin{array}{l}186 \\
(55.0 \%)\end{array}$ \\
\hline \multirow[t]{5}{*}{$\begin{array}{l}\text { Thyroid Hormone } \\
\text { Level }\end{array}$} & $\begin{array}{l}(\mathrm{TSH}) \\
( \pm \mathrm{SD})\end{array}(\mu \mathrm{lU} / \mathrm{mL})$, Mean & $\begin{array}{l}2.29 \\
( \pm 1.933)\end{array}$ & $\begin{array}{l}1.98 \\
( \pm 1.78)\end{array}$ & $\begin{array}{l}2.57 \\
( \pm 2.26)\end{array}$ & $\begin{array}{l}2.19 \\
( \pm 1.73)\end{array}$ \\
\hline & $\begin{array}{l}\text { Total Thyroxine (T4) } \\
\text { (nmol/L), Mean ( } \pm \text { SD) }\end{array}$ & $\begin{array}{l}94.98 \\
( \pm 19.49)\end{array}$ & $\begin{array}{l}93.51 \\
( \pm 17.49)\end{array}$ & $\begin{array}{l}95.72 \\
( \pm 20.60)\end{array}$ & $\begin{array}{l}94.83 \\
( \pm 19.21)\end{array}$ \\
\hline & $\begin{array}{l}\text { Total Triiodothyronine } \\
(\text { T3) (nmol/L), Mean } \\
( \pm S D)\end{array}$ & $\begin{array}{l}1.52 \\
( \pm 0.33)\end{array}$ & $\begin{array}{l}1.32 \\
( \pm 0.26)\end{array}$ & $\begin{array}{l}1.48 \\
( \pm 0.32)\end{array}$ & $\begin{array}{l}1.59 \\
( \pm 0.33)\end{array}$ \\
\hline & $\begin{array}{l}\text { Free T4 (pmol/L), Mean } \\
( \pm S D)\end{array}$ & $\begin{array}{l}16.68 \\
( \pm 2.81)\end{array}$ & $\begin{array}{l}16.71 \\
( \pm 2.60)\end{array}$ & $\begin{array}{l}16.64 \\
( \pm 2.78)\end{array}$ & $\begin{array}{l}16.71 \\
( \pm 2.90)\end{array}$ \\
\hline & $\begin{array}{l}\text { Free T3 }(\mathrm{pmol} / \mathrm{L}), \text { Mean } \\
( \pm S D)\end{array}$ & $\begin{array}{l}4.30 \\
( \pm 0.79)\end{array}$ & $\begin{array}{l}3.77 \\
( \pm 0.53)\end{array}$ & $\begin{array}{l}4.16 \\
( \pm 0.77)\end{array}$ & $\begin{array}{l}4.52 \\
( \pm 0.78)\end{array}$ \\
\hline \multicolumn{2}{|c|}{ Glucose (mmol/L), Mean $( \pm \mathrm{SD})$} & $\begin{array}{l}7.03 \\
( \pm 1.3)\end{array}$ & $\begin{array}{l}7.12 \\
( \pm 1.3)\end{array}$ & $\begin{array}{l}6.93 \\
( \pm 1.2)\end{array}$ & $7.08( \pm 1.3)$ \\
\hline
\end{tabular}




\begin{tabular}{|c|c|c|c|c|}
\hline & Total & $\begin{array}{l}\text { Group A } \\
\text { (Above } \\
80 \text { ) }\end{array}$ & $\begin{array}{l}\text { Group B } \\
\text { (65-80 } \\
\text { Years) }\end{array}$ & $\begin{array}{l}\text { Group C } \\
\text { (Below } 65 \\
\text { Years) }\end{array}$ \\
\hline $\begin{array}{l}\text { C-Reactive Protein } \\
(\mathrm{mg} / \mathrm{dL}) \text {, Mean } \\
( \pm \mathrm{SD})\end{array}$ & $\begin{array}{l}1.79 \\
( \pm 0.95)\end{array}$ & $\begin{array}{l}2.13 \\
( \pm 0.81)\end{array}$ & $\begin{array}{l}1.91 \\
( \pm 1.02)\end{array}$ & $\begin{array}{l}1.66 \\
( \pm 0.72)\end{array}$ \\
\hline \multicolumn{5}{|l|}{$\begin{array}{l}\text { Severity } \\
\text { Assessment }\end{array}$} \\
\hline $\begin{array}{l}\text { NIHSS, Median } \\
\text { (IQR) }\end{array}$ & $3(1-5)$ & $3(1-7)$ & $3(1-5)$ & $2(1-5)$ \\
\hline
\end{tabular}

\section{Spearman's Rank Correlation}

Spearman's Rank Correlation was performed to evaluate the association and the degree of correlation between thyroid-related hormones and NIHSS scores on admission in each age group. The correlation with a P-value less than 0.05 was considered to show a significant association between the two factors. The absolute value of the correlation coefficient (rho) shows the degree or magnitude of association. Results from Spearman's Rank Correlation were summarized in Table 2.

Table 2

Correlation between Thyroid Related Hormones and NIHSS on Admission

\begin{tabular}{|lllllllll|}
\hline & \multicolumn{2}{l}{ Whole Population } & \multicolumn{2}{l}{ Above 80 Year } & \multicolumn{2}{l}{ 65-80 Years } & \multicolumn{2}{c|}{ Below 65 Years } \\
\hline & rho & P-value & rho & P-value & rho & P-value & rho & P-value \\
\hline T3 & -0.122 & 0.003 & -0.251 & 0.005 & -0.122 & 0.046 & -0.072 & 0.187 \\
\hline T4 & 0.003 & 0.947 & -0.005 & 0.967 & -0.04 & 0.578 & 0.042 & 0.442 \\
\hline TSH & -0.135 & 0.01 & -0.126 & 0.312 & -0.276 & $<0.001$ & -0.162 & 0.003 \\
\hline fT3 & -0.232 & $<0.001$ & -0.45 & 0.005 & -0.337 & $<0.001$ & -0.179 & 0.022 \\
\hline fT4 & -0.054 & 0.341 & 0.038 & 0.822 & -0.231 & 0.013 & 0.083 & 0.289 \\
\hline
\end{tabular}

\section{T3 and NIHSS Score}

T3 values and NIHSS scores were negatively correlated in the whole population group and in the elderly patient groups (both in the Above 80 Group and 65-80 Group, with P-values less than 0.05). The association between T3 and NIHSS score in the Below 65 Group was not statistically significant with a Pvalue of 0.187 . Same tests were performed on different age grouping methods, such as Below 70 Group, Below 60 Group, 45-65 Years Group. The resulting P-values were generally greater than 0.05 (not presented in Table 2). The results showed that the association between T3 and NIHSS score was significant in all but the Below 65 Years Group. A lower T3 value upon admission didn't necessarily indicate a higher NIHSS score or worse disease severity for younger patients. 
It was also noted that the absolute value of the correlation coefficient in the Above 80 Group was greater than that in the 65-80 Group. It could suggest a relatively stronger negative correlation between T3 and NIHSS in the Above 80 Group than that in the 65-80 Group. It could also be interpreted that the same deviation from the median T3 values $(\triangle T 3)$ would lead to a greater alteration from the median NIHSS scores ( $\triangle$ NIHSS) in the Above 80 Group than the $\triangle$ NIHSS in the 65-80 Group. Although, a correlation coefficient less than 0.3 often indicated a relatively weak association.

\section{T4 and NIHSS Score}

T4 values and NIHSS scores were shown to be not significantly correlated, with P-values in all three groups greater than 0.05 .

\section{TSH and NIHSS Score}

TSH values and NIHSS were negatively correlated in the whole population analysis (P-value of 0.01) and the younger patient groups (65-80 Group and the Below 65 Group with P-values of $<0.001$ and 0.003 respectively). The correlation between the two factors was not significant in the Above 85 Group (P-value of 0.312). The magnitude of association between the two factors was weaker in Below 65 Group than that in the 65-80 Group, and the weakest in the whole population $(r=-.276, r=-.162$, and $r=-.135$ respectively).

\section{fT3, fT4, and NIHSS Score}

The fT3 values were shown to be inversely associated with NIHSS scores in all age groups ( $p$ values of $<0.001,0.005,<0.001$, and 0.022 ). The magnitudes of correlation decreased with decreasing age

(expressed by the decreasing absolute values of the correlation coefficient, $r=-0.45,-0.337$, and -0.179 ). It could be interpreted that the same deviation from the median fT3 value ( $\triangle \mathrm{fT} 3)$ would be correlated to greater change in NIHSS ( $\triangle \mathrm{NIHSS}$ ) in the elder stroke patients than that in the younger patients. The correlation between the fT4 and NIHSS score was only significant in the 65-80 Years Group with a P-value of 0.013 . This could mean that for admitted stroke patient between 65 and 80 years old, the fT 4 value could be a clinically meaningful biomarker in relation to disease severity and functional outcomes. This association would not be significant in other age groups.

\section{Discussion}

As Acute Ischemic Stroke (AIS) becomes a leading cause of mortality and long-term disability, many researchers have focused on preventative measures as well as cutting-edge treatment options for this disease. These treatment options could be dependent on accurate assessment of stroke severity as well as the correct prediction of functional outcomes. The optimal therapeutic practice could then be provided to stroke patients and health care resources could be sufficiently allocated.

Accurate assessment and prognostication could not be performed without the evaluation of biomarkers. Various blood serum biomarkers have been evaluated for their prognostic values, including thyroid axis hormones, copeptin, CRP, glutamate, glucose, and vitamin D [17-20]. Among these values, the thyroid- 
related hormones could be easily tested with stroke patients' peripheral blood and they are known to play a neural protective role in brain development, morphogenesis, neuron maturation process, and inflammation reduction [21].

A stroke event would trigger the stress response in the body resulting in blood serum level changes. The body responds to the stress by accumulating pro-inflammatory cytokines (IL-1, IL-6, IL-10, TNF-2, etc.) that would interfere with normal thyroid hormone metabolism leading to changes in hormone levels [22].

Researches have focused on the physiological relevancy of thyroid hormone profiles. T3 is known to be negatively correlated to stroke severity (expressed as NIHSS scores) and some studies have concluded that fT3 and T3/T4 ratios are negatively associated with the NIHSS scores, but results are not confirmed in other researches [9-14]. The relationship between other thyroid hormones (TSH, T4, and fT4) and NIHSS score have inconclusive results. Most of the previous analyses have been focusing on the whole population analysis to explore the predictive and prognostic values. Those studies did not take the effect of aging into account, or they simply adjusted age as a confounding factor in the multivariate analysis.

Aging is also a significant prognostic factor concerning severity and outcome in stroke patients [23]. The elderly patients have on average increased or unchanged levels of T4 and decreased serum T3, due to declined conversion from T4 to T3 by deiodinase [24]. The special physiologic status of aged patients sometimes leads to subclinical hypothyroidism, which complicates the assessment of thyroid status with precision. A low T3 value of elderly patients may be the result from stroke stress response, or it could be related to subclinical hypothyroidism caused by age.

Li et al have conducted a set of statistical analyses on stroke victims in two age groups, the below- 65 group and the over-65 group [15]. It was concluded that the prognostic value of T3 for a poor functional outcome is clinically more meaningful in the over- 65 group. But the study did not mention the degree of association between different factors and stroke severity in different age groups. Also, there was few studies focusing on the effect of aging in patients over 80 years old. It was clinically meaningful to explore the prognostic value of thyroid-related hormones in stroke patients over 80 years old, taking into account the complication of the special physiologic status.

Aging can significantly affect the results and complicate the analysis.Besides conducting a whole population analysis, more delicate age-dependent grouping methods could be used to reveal the true and accurate association between biomarkers and outcomes.

In our analysis, the correlation results vary in different age groups. For patients above 80 years old, only T3 and fT3 were negatively correlated to NIHSS scores (both P-values $=0.005$ ). In the 65-80 Group, four out of the five thyroid hormones analyzed (except for T4) were found to have a significantly negative association with the NIHSS scores. In the Below 65 group, the TSH and fT3 were found to have a significant relation to stroke severity assessment. Looking at the correlation coefficients across different age groups, the absolute values of rho are lower in the younger age group (the 65-80 Years Group) than that in the Above 80 group, suggesting smaller magnitudes of correlation in younger age groups. For fT3 
values across the three age groups, the absolute values of rho were lower in younger age groups, suggesting an increasing magnitude of correlation as age went up.

The age-dependent grouping method could be potentially applied to other analyses for disease severity assessment and prognostication. A non-significant association between any two factors in the entire population might present significant results in sub-group analysis.

However, the association between endocrine alternation does not necessarily imply causation. It is still debatable whether thyroid hormones disorder should be treated as part of the therapeutic process after stroke [25].

Although no data on the measurements of functional outcomes such as mRS or NIHSS at discharge were available in the study, there are a variety of studies suggesting that initial NIHSS scores are directly associated with functional outcomes upon discharge and in the follow-up visits [9-14].

There are a few limitations to this study. Firstly, this was a single-center study that could be inevitably biased towards a certain set of populations. Secondly, the nature of a retrospective analysis limited the ability to obtain more sufficient data, such as NIHSS score and mRS upon hospital discharge and in follow-up visits. More than one thyroid hormone testing after the initial admission test could help reflect more dynamic changes because blood serum levels had large variations during a day. Thirdly, although the NIHSS was evaluated by a neurologist, there might still be observer variability and human error in the assessment thus affecting the accuracy. Lastly, a larger cohort and multiple center population analysis would potentially more statistical insight into the association and the magnitude of the correlation between thyroid hormones and disease severity, functional outcomes, and long-term survival.

\section{Conclusions}

Despite inherent and innate limitations, it was cautiously asserted that aging had a significant effect on the association and the magnitude of correlation between thyroid hormones and stroke outcomes. The more delicate age-dependent grouping methods could provide more accurate and clinically meaningful insights into the prognostic values of biomarkers.

\section{Abbreviations}

ACD - Acute Cerebrovascular Disease

AIS - Acute Ischemic Stroke

TSH - Thyroid-Stimulating Hormones

T3 - Total Triiodothyronine

T4 - Total Thyroxine 
free T3 - free Total Triiodothyronine

free T4 - free Total Thyroxine

NIHSS - National Institute of Health Stroke Scale

\section{Declarations}

\section{Ethics Approval and Consent to Participate}

The study was approved by the Research Ethics Committee of the Hebei General Hospital. All methods were carried out in accordance with relevant guidelines and regulations. Informed consent was obtained from all subjects and/or their legal guardian(s).

\section{Consent for Publication}

Not applicable.

\section{Availability of Data and Materials}

All data generated or analysed during this study are included in this published article and its supplementary information files.

\section{Competing Interests}

There are no competing interests among authors.

\section{Funding}

Not Applicable

\section{Authors' Contributions}

\section{Declarations of interest}

None

\section{Funding}

This research did not receive any specific grant from funding agencies in the public, commercial, or notfor-profit sectors.

\section{Authors' Contributions}

Yamin Lu made substantial contributions to the conception, design and revision of the work. Fang Chen performed the data collection and drafted the work. Feng Mo, Guangxia Liu, and Zhan Hou made 
substantial contribution to the analysis and interpretation of data. Lianchun Zhao and Lin Liu performed the translation and proof-reading of the article. All authors read and approved the final manuscript.

\section{Acknowledgement}

Special thanks to Hebei General Hospital for the help in study modification and data acquisition.

\section{References}

1. GBD 2015 Mortality and Causes of Death Collaborators. "Global, regional, and national life expectancy, all-cause mortality, and cause-specific mortality for 249 causes of death, 1980-2015: a systematic analysis for the Global Burden of Disease Study 2015." Lancet (London, England) vol. 388,10053 (2016): 1459-1544. doi:10.1016/S0140-6736(16)31012-1

2. Deng, Wen-Jing et al. "Relationship between procalcitonin serum levels and functional outcome in stroke patients." Cellular and molecular neurobiology vol. 35,3 (2015): 355-361. doi:10.1007/s10571014-0131-0

3. lervasi, Giorgio et al. "Low-T3 syndrome: a strong prognostic predictor of death in patients with heart disease." Circulation vol. 107,5 (2003): 708-13. dor:10.1161/01.cir.0000048124.64204.3f

4. Scoscia, Elvio et al. "Low triiodothyronine (T3) state: a predictor of outcome in respiratory failure? Results of a clinical pilot study." European journal of endocrinology vol. 151,5 (2004): 557-60. doi:10.1530/eje.0.1510557

5. Plikat, Katharina et al. "Frequency and outcome of patients with nonthyroidal illness syndrome in a medical intensive care unit." Metabolism: clinical and experimental vol. 56,2 (2007): 239-44. doi:10.1016/j.metabol.2006.09.020

6. Bunevicius, Adomas et al. "Low triiodothyronine syndrome as a predictor of poor outcomes in patients undergoing brain tumor surgery: a pilot study: clinical article." Journal of neurosurgery vol. 118,6 (2013): 1279-87. doi:10.3171/2013.1.JNS121696

7. Samuels, Martin A. "The brain-heart connection." Circulation vol. 116,1 (2007): 77-84. doi:10.1161/CIRCULATIONAHA.106.678995

8. Boelen, A et al. "Thyroid hormone receptor $\beta$ mediates acute illness-induced alterations in central thyroid hormone metabolism." Journal of neuroendocrinology vol. 21,5 (2009): 465-72. doi:10.1111/j.1365-2826.2009.01863.x

9. Martin-Schild, Sheryl et al. "Zero on the NIHSS does not equal the absence of stroke." Annals of emergency medicine vol. 57,1 (2011): 42-5. doi:10.1016/j.annemergmed.2010.06.564

10. Xu, Xiao-Yan et al. "Alteration of Thyroid-Related Hormones within Normal Ranges and Early Functional Outcomes in Patients with Acute Ischemic Stroke." International journal of endocrinology vol. 2016 (2016): 3470490. doi:10.1155/2016/3470490

11. Akhoundi, Fahimeh $\mathrm{H}$ et al. "Favorable functional outcomes in acute ischemic stroke patients with subclinical hypothyroidism." Neurology vol. 77,4 (2011): 349-54. 
doi:10.1212/WNL.0b013e3182267ba0

12. Xu, Xiao-Yan et al. "Alteration of Thyroid-Related Hormones within Normal Ranges and Early Functional Outcomes in Patients with Acute Ischemic Stroke." International journal of endocrinology vol. 2016 (2016): 3470490. doi:10.1155/2016/3470490

13. Bunevicius, Adomas et al. "Ischemic stroke functional outcomes are independently associated with C-reactive protein concentrations and cognitive outcomes with triiodothyronine concentrations: a pilot study." Endocrine vol. 45,2 (2014): 213-20. doi:10.1007/s12020-013-9958-2

14. Forti, Paola et al. "Thyroid function tests and early outcomes of acute ischemic stroke in older euthyroid patients." Experimental gerontology vol. 61 (2015): 8-14. doi:10.1016/j.exger.2014.11.011

15. Li, Lei-Qing et al. "The prognostic value of total T3 after acute cerebral infarction is age-dependent: a retrospective study on 768 patients." BMC neurology vol. 19,1 54. 5 Apr. 2019, doi:10.1186/s12883019-1264-z

16. Bremner, Alexandra $\mathrm{P}$ et al. "Age-related changes in thyroid function: a longitudinal study of a community-based cohort." The Journal of clinical endocrinology and metabolism vol. 97,5 (2012): 1554-62. doi:10.1210/jc.2011-3020

17. Deng, Wen-Jing et al. "Relationship between procalcitonin serum levels and functional outcome in stroke patients." Cellular and molecular neurobiology vol. 35,3 (2015): 355-361. doi:10.1007/s10571014-0131-0

18. Capes, S E et al. "Stress hyperglycemia and prognosis of stroke in nondiabetic and diabetic patients: a systematic overview." Stroke vol. 32,10 (2001): 2426-32. doi:10.1161/hs1001.096194

19. Kannel, W B et al. "White blood cell count and cardiovascular disease. Insights from the Framingham Study." JAMA vol. 267,9 (1992): 1253-6.

20. T. Rundek and R. L. Sacco, "Outcome following stroke," in Stroke Pathophysiology, Diagnosis, and Management, J. P. Mohr, D. W. Choi, J. C. Grotta, B. Weir, and P. A. Wolf, Eds., chapter 3, pp. 35-57, Churchill Livingstone, New York, NY, USA, 5th edition, 2004.

21. Alevizaki, Maria et al. "Hypothyroidism as a protective factor in acute stroke patients." Clinical endocrinology vol. 65,3 (2006): 369-72. doi:10.1111/j.1365-2265.2006.02606

22. Boelen<bi $>,</$ bi $>$ A <bi>et al.</bi> "Thyroid hormone receptor $\beta$ mediates acute illness-induced alterations in central thyroid hormone metabolism<bi $>$." $</$ bi $>$ Journal of neuroendocrinology $<\mathrm{bi}>\mathrm{vol}$. $</$ bi $>21<$ bi $>,</$ bi $>5<$ bi $>(</$ bi $>2009<$ bi $>):</$ bi $>465-72<$ bi $>$. doi: $</$ bi $>$ 10

$.1111 /$ j. 1365-2826.2009.01863.x

23. Bremner $<\mathrm{bi}>,</$ bi $>$ Alexandra $\mathrm{P}<\mathrm{bi}>$ et al. " $<$ /bi $>$ Age-related changes in thyroid function: a longitudinal study of a community-based cohort<bi>."</bi> The Journal of clinical endocrinology and metabolism $<$ bi $>$ vol. $</$ bi $>97<$ bi $>,</$ bi $>5<$ bi $>(</$ bi $>2012<$ bi $>):</ b i>1554-62<b i>$. doi $:</$ bi $>$ 10

$.1210 /$ jc. $2011-3020$

Page $13 / 14$ 
24. Gesing $<$ bi $>,</$ bi $>$ Adam $<$ bi $>$ et al. "The thyroid gland and the process of aging; what is new?." Thyroid research vol. 5,1 16. $24 \mathrm{Nov} .</ \mathrm{bi}>2012<\mathrm{bi}>$, doi:</bi>

10

$.1186 / 1756-6614-5-16$

25. De Groot, Leslie J. "Non-thyroidal illness syndrome is a manifestation of hypothalamic-pituitary dysfunction, and in view of current evidence, should be treated with appropriate replacement therapies." Critical care clinics vol. 22,1 (2006): 57-86, vi. doi:10.1016/j.ccc.2005.10.001

\section{Figures}

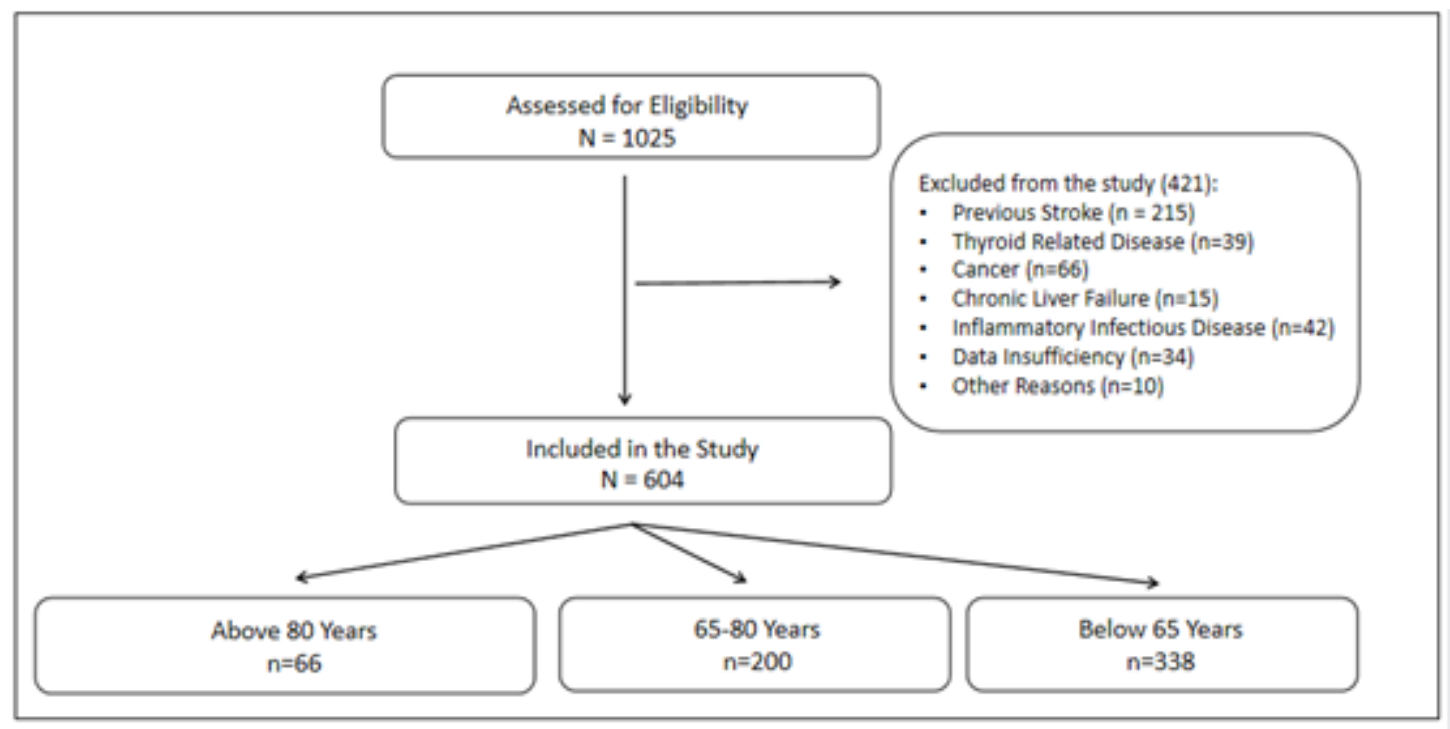

Figure 1

Flow Chart Demonstrating Study Design 